\title{
EaD, Cérebro Global e Engenharia Reversa do Conhecimento: Modelo Hipotético de Plataforma Horizontal e o Processo de Aprendizagem a Partir das TIC \\ Distance Education, Brain Global and Reverse Engineering of Knowledge: The Horizontal Platform Model and The Learning Process from ICT
}

Gustavo Luiz Gava1

${ }^{1}$ Professor e Pesquisador, NFH (Núcleo de Formação Humana), Universidade Positivo. R. Prof. Pedro Viriato Parigot de Souza, 5300 - Curitiba - PR - Brasil. gustavoluizgava@hotmail.com

\section{Resumo}

Este artigo apresenta o núcleo básico acerca do entendimento do Cérebro Global, bem como discute a necessidade de uma engenharia reversa do conhecimento no modelo da Educação a Distância nos países que avistam no EaD (Ensino a Distância) o futuro da educação. O fenômeno do Cérebro Global tornou-se possível graças à revolução causada pelas novas tecnologias da informação e comunicação (TIC) a partir das décadas de 1970 e 1990. Com todos esses impactos fenomênicos em nível cerebral, pode-se perceber que a maneira pela qual se processa a informação passou a ser horizontal e que o processo de aprendizagem do cérebro humano fora modificado cognitivamente. Para alcançar um nível de reflexão ética e ontológica por trás dessas questões, é necessária uma filosofia da Educação a Distância. E, ao mesmo tempo, é preciso estar ciente de que o salto cerebral não se trata mais de uma metáfora, mas sim de uma realidade da evolução tecnológica e humana que se encontra num mesmo processo emergente: a evolução concomitante. As dificuldades encontradas por diversos países que investiram no EaD tendo como proposta oferecer um novo modelo educacional têm origem na carência de emancipar o zeitgeist pedagógico vertical e instrumental. Assim, encerra-se o artigo com uma proposta hipotética (modelo de ambiente virtual de aprendizagem), ainda em construção, que fomenta potencializar o cérebro global no ensino a distância.

Palavras-chave: Cérebro Global, Engenharia Reversa do Conhecimento, Filosofia da Educação a Distância. 


\section{Distance Education, Brain Global and Reverse Engineering of Knowledge: The Horizontal Platform Model and The Learning Process from ICT}

\section{Abstract}

This article presents the basic core about the Global Brain understanding, as well as the need for the so called reverse engineering of knowledge for the model of distance education in the countries that foster distance education as the future of education. The Global Brain phenomenon became possible due to the revolution caused through the new information and communication technologies (ICT) in the 1970s and 1990s. With all these phenomenal impact in brain level it is possible to realize that the way in which information is processed has become horizontal and the learning process of the human brain had been modified cognitively. In order to achieve a level of ethical and ontological reflection behind these issues, a philosophy of distance education is required. At the same time, it is necessary to be aware that the brain jumping is no more than a metaphor, but a reality of technological and human evolution which is in the same emergent process: concomitant evolution. The difficulties encountered by many countries which had invested in distance learning as a proposal to offer a new educational model came from the lack of emancipating the vertical and instrumental teaching zeitgeist. Therefore, the article is concluded with a hypothetical proposal (a model of virtual learning environment), still under construction, which seeks to enhance the Global Brain in distance learning.

Keywords: Global Brain, Reverse Engineering of Knowledge, Philosophy of Distance Education..

\section{Introdução}

Atualmente, sabe-se que um dos principais desafios encontrados no modelo presencial de ensino no Brasil e no mundo é o processo de aprendizagem mediante as céleres mudanças sociais e tecnológicas. O processo da globalização exigiu cada vez mais que os sujeitos se especializassem em suas áreas de atuação, bem como estivessem mais preparados às rápidas mudanças para se manter no mercado de trabalho. Na mesma velocidade, os avanços tecnológicos influenciaram direta e indiretamente a vida de cada cidadão. $\mathrm{O}$ EaD tendo como proposta uma alternativa à formação acadêmica até então exclusivamente presencial eclode nessa seara passando por vários momentos anteriores ${ }^{1}$. Contudo, vale ressaltar que não se trata de uma solução ao ensino presencial, mas sim de atender uma nova demanda/realidade além do modelo presencial e que se pauta pelas tecnologias disponíveis exclusivamente em ambiente virtual. Ao contrário desse apontamento, só o futuro poderá dizer.

Todavia, foi devido ao surgimento da internet e dos primeiros modelos de AVA (ambiente virtual de aprendizagem) que o EaD se tornou forte alternativa educacional à realidade do novo século que se inauguraria: o século XXI. Assim como na globalização, as fronteiras do ensino foram rompidas e, a partir daí, houve a possibilidade de levar conteúdo a distância. Isso tudo influenciou diretamente o processamento cognitivo dos cérebros humanos. E esse fenômeno hoje é conhecido por Cérebro Global.

1 Os momentos anteriores do EaD surgiram primeiramente por meio de correspondência. Logo em seguida, por transmissão via rádio e TV até o surgimento da internet e a sua grande revolução. 
Ou seja, entende-se por Cérebro Global as mudanças cerebrais no processamento cognitivo da informação desde o surgimento da internet e os avanços das tecnologias da informação e comunicação (TIC).

Em pleno século XXI, pode-se observar grupos pensantes que se preocupam com essa problemática, tendo em vista encontros e discussões importantes que instituições e órgãos de pesquisa em EaD chancelam. Todavia, como lidar com a nova realidade e demanda do EaD no âmbito do ensino superior? Entende-se que o EaD é fruto da revolução noética², fenômeno desse novo século que possibilitou diversos a atores sociais ter acesso ao conhecimento, ao ensino e ao espaço acadêmico numa alternativa além do modelo presencial.

É possível observar que muitos problemas (evasão, reprovação, desinteresse, incompreensão de conteúdo, entre outros) estão relacionados mais detalhadamente com a maneira como entendemos o EaD. Mas em tal questão há dois pontos fulcrais: 1) a sensação de não lugar, anunciada por Lévy (1996), entre professores e estudantes; e 2) a (in)compreensão fenomenológica que antecede à implementação sólida da cultura EaD. O fenômeno é o próprio Cérebro Global. Contemporaneamente, em EaD, caso não se acompanhem as principais mudanças em nível cerebral - o processamento informacional - influenciadas pelas TIC e pautadas numa vertente neurofilosófica ${ }^{3}$, corre-se o risco de incorrer num processo inverso de fazer acontecer o EaD.

Pode-se observar que foram criadas novas metodologias, plataformas e tantas outras ferramentas baseadas nos avanços das TIC. Contudo, algumas instituições de ensino tendem a estar pautadas algumas vezes exclusiva e economicamente pelas leis do mercado. Isto é, os serviços e os produtos tecnológicos, bem como suas metodologias específicas de aprendizagem - quando desenvolvidas pela própria instituição de ensino -, seguem (ou se preocupam, primeiramente) o intuito de alcançar um modelo de gestão enxuta ${ }^{4}$. E, como resultado final, aquilo que se oferece em ambiente virtual, em espaço cibernético (Lévy, 1996), pode acarretar a sensação de não pertencimento àqueles que usufruirão direta e diariamente, haja vista que o conceito e a abstração autógena ${ }^{5}$ do virtual, algumas vezes, fogem dos padronizados modelos desenvolvidos exclusivamente sob o espectro apenas do mercado. Ou seja, no dia a dia, a relação com a internet e com as TIC por parte desses atores sociais é horizontal e sintagmática. Ou melhor, trata-se de um ator sintagmático virtual ${ }^{6}$.

Outra advertência necessária a se abordar é o modelo educacional intrínseco a tais empreendimentos pedagógicos, que ainda persiste configurado no padrão vertical de ensino. Ou seja, o paradoxo do EaD se escancara a partir do momento em que são criadas "distorções"; uma vez que, mesmo com o avanço das novas tecnologias, leiautes cleans, entre outros ferramentais, a maneira como se pensa, a fim de sistematizar o processo de ensino, é vertical e, às vezes, obsoleta. Esse

2 Fenômeno que estuda a dimensão humana pelas suas características subjetivas, como por exemplo a consciência, a criatividade, a intuição, entre outros. A informação, o conhecimento e o pensamento passam a ser vistos como medida de valor humano. Para Abbagnano (2012, p. 834), "foi assim que Hamilton denominou a parte da lógica que estuda 'as leis fundamentais do pensamento', que são os quatro princípios: identidade, contradição, terceiro excluído e razão suficiente (Lectures on Logic, V, I, p. 72)".

3 Vertente filosófica que busca entender a problemática relação mente-cérebro baseada de forma interdisciplinar nas pesquisas das Ciências Cognitivas e da Neurociência Cognitiva.

4 Modelo que preza inicialmente reduzir e cortar custos. Decisões essas que, às vezes, podem ir de encontro às necessidades fenomênicas humanas emergentes, pois se baseia em primeiro lugar nas leis do mercado: o lucro sobre o serviço/produto massivamente oferecido na praça.

5 O termo refere-se ao novo ator social do século XXI. Sujeito este que se engendra a si mesmo. Detém seu próprio conhecimento.

6 Sujeito que, a partir do acesso à rede virtual, é capaz de criar seu próprio território. Esse mesmo sujeito, igualmente, é cocriador de conteúdo. Por exemplo, blogs, canais em plataformas como Youtube, Facebook, entre outras. Sua relação em rede é horizontal e holocentrada em experiências e trocas de informações diversas. É o prelúdio à Web 3.0 - considerada por especialistas da I. A. (inteligência artificial), como a web semântica, em que homem e máquina passam a aprender concomitantemente. 
mesmo paradoxo anula tanto a estrutura pedagógica como também a estrutura econômica para sustentar o EaD.

O ensino modular fechado, o modelo vertical monológico, transmissivo, prejudicam diretamente a atividade dialógica (Bakhtin, 1997; Vygotsky, 1998). Inclusive pode comprometer o sucesso de qualquer empreendimento didático-pedagógico. No atual momento do EaD, plataformas on-line que disponibilizam módulos conteudísticos em série ainda podem contribuir para um modelo monológico virtual. Mas a comunicação criativa da realidade cotidiana entre discente e docente é comprometida - há um déficit no estímulo cognitivo-motivacional do Cérebro Global (Gava, 2010), haja vista que a estrutura metodológica se preocupa, algumas vezes, à extensão do conteúdo definido (Freire, 2011). O ensino vertical é esse modelo que preza o conteúdo distribuído em série e atividades avaliativas de maneira exclusiva e metodologicamente monológicas.

Recorremos ao uso dos modelos AVA mais avançados - com evidente potencial de horizontalidade com base num cerne metodológico de proposta serial. E, mesmo quando há os momentos das paradas para prática, como por exemplo os fóruns avaliativos (dissertativos ou objetivos), os fóruns tira-dúvidas (técnicos ou conteudísticos) e os jogos on-line, ainda assim, encontram-se metodologicamente insuficientes quando se trata de lidar com as possibilidades de ativar o cérebro global, de uma estrutura/base neurofilosófica e, principalmente, de lidar com o fenômeno da anarquia on-line. Deve-se atentar para que os conteúdos disponibilizados on-line não sejam meramente especializados. Advertência esta proferida por Morin (2006) e que se aplica às plataformas de aprendizagem: "a hiperespecialização mutila o saber"; seja no ensino presencial e/ou no ensino virtual:

A internet é o maior experimento da história envolvendo anarquia. A cada minuto, centenas de milhões de pessoas criam e consomem uma incalculável soma de conteúdo digital em um universo on-line que não é limitado pelas leis terrestres (Schmidt \& Cohen, 2013, p. 11).

Contudo, não se quer dizer aqui que plataformas como BlackBoard, Moodle, Sakai etc. não funcionem. Muito pelo contrário, são ferramentas tecnológicas com potencial de uso possivelmente inexplorado para ativar metodologicamente o cérebro global. Afirmar que tais ferramentas não funcionam seria estar desvinculado da própria realidade do EaD. Porém outra questão central proposta neste artigo (além do fenômeno do Cérebro Global ao EaD) são as metodologias aplicadas a essas plataformas. Principalmente quando se trata de potencializar o processo de ensino-aprendizagem entre docentes e discentes por meio do potencial das TIC. Por isso, o corpo pensante das instituições que apostam no EaD deve se preocupar com esses fenômenos do Cérebro Global que antecedem a instrumentalização.

Da mesma maneira, não estamos desmerecendo uma variedade de projetos assertivos (para esse primeiro momento) usados recentemente pelas instituições que estão apostando no EaD. É importante afirmar que o intuito deste artigo é claramente apontar o valimento de uma base neurocientífica e neurofilosófica para que se possa entender os fenômenos ontológicos que galgam o percurso do EaD. O LMS (learning management system) e seus conteúdos digitais disponíveis com base numa metodologia específica escolhida e/ou elaborada pela instituição de ensino - juntamente com toda a equipe de tecnologia da informação - são prioridades voltadas ao mercado e-learning e seu diferencial a ser oferecido. O que se ressalta aqui é justamente os elementos ontológicos antecedentes que se deve considerar para uma nova fase em EaD - um segundo tempo, pode se dizer assim.

De maneira complementar, pedagógica e economicamente falando, ter acesso às melhores tecnologias/ metodologias, aos melhores modelos de gestão de produção enxutos, bem como aos melhores currículos docentes para possibilitar a educação a distância não garante sobrevida às instituições de ensino superior que buscam obter reconhecimento e excelência em educação virtual neste século e num ambiente de 
anarquia on-line. A carência para refletir o EaD no Brasil (e no mundo) é resultado da exigência de entendimento fenomenológico que perpassa nosso dia a dia sobre as seguintes pautas: o campo ontológico (o que é tecnologia e o que é informação?); o campo do conhecimento (quem é o novo sujeito vivente do Terceiro Milênio?); e o campo neurofilosófico (como se dá o funcionamento informacional do Cérebro Global na relação mente e cérebro no processo de aprendizagem virtual?). A ausência de uma dessas pautas na tríade apresentada pode revelar como ainda é pensado o EaD de baixo para cima (Gava, 2016).

Isto é, primeiramente se pensa na metodologia a ser criada, na tecnologia de ponta a ser usada, na melhor produção enxuta inicial de mercado, entre outras. Contudo, é esquecido o fenômeno: a atual relação de nossos cérebros e o salto encefálico no processamento cognitivo-informacional. Instrumentalizar o EaD é muito diferente de refletir sobre os fenômenos que compõem essa nova realidade ensino -aprendizagem do século XXI. Pensar em como conquistar esse novo público - atores ativos, detentores de conhecimento e não mais tábulas rasas - que busca acesso ao conhecimento por meio do EaD. E, principalmente, como anunciou um dos principais autores da revolução noética, Halévy (2010), esses são os novos atores sociais deste Terceiro Milênio. São os atores transientes desse novo tempo em educação virtual que usufruem e criam informações quase que em tempo real - um prelúdio à Web 4.0, como será visto na seção 3 desse artigo.

\section{Como identificar a necessidade de uma engenharia reversa do conhecimento: o EaD em dois tempos}

A partir da década de 1980 (era digital) e da década de 1990 (decênio cerebral), aconteceram inúmeros adventos das neurociências, da informática, da psicologia experimental, da inteligência artificial, assim como surgiram estudos sobre redes neurais e discussões pedagógicas/filosóficas destinadas à cognição humana, especificamente no que concerne à relação de aprendizado mente-cérebro, que voltam ao campo de discussão. O que é possibilitado não apenas pela era digital, mas também pela sinergia que essa mesma contribuição estabelece para o novo milênio.

O termo "era digital" se refere ao final dos anos de 1980. Para Veen e Vrakking (2009), foi a partir desse ano que a sociedade passou por mudanças socioeconômicas impactantes graças ao surgimento da tecnologia digital. E, não menos importante, com o processo da globalização e todos os seus avanços tecnológicos. "Geração digital refere-se ao fato de as crianças atuarem em mundos digitais (SIC) on-line ou lidarem com informações digitais" (Veen \& Vrakking, 2009, p. 28-29). Com a chegada da era digital houve o surgimento de uma série de serviços e produtos que começavam a oferecer plataforma de comunicação em redes globais. Segundo pesquisas de Prensky (2001), já no início dos anos 2000, obtiveram-se resultados descomunais acerca do número de horas que os estudantes universitários passavam em frente ao computador.

Já a década do cérebro se refere ao início dos anos de 1990. Segundo Gardner (1994; 1996), foi a partir da inteligência artificial, da filosofia da mente e da ciência cognitiva que, desde os seus primórdios em 1947, houve um salto nos estudos sobre a relação mente-cérebro, assim como na forma de entendimento da inteligência humana, suas estruturas e do processo de aprendizado do cérebro humano. Com a chegada dos anos de 1990 e as novas tecnologias, passou-se a conhecer melhor, por meio de processos de imagiologia, o próprio cérebro e seus fenômenos internos.

Esse fenômeno em massa e todas as suas consequências foram denominados pelo físico, filósofo e cientista da complexidade, o francês Marc Halévy, como revolução noética. Para esse autor, tal fenômeno trata não apenas da velocidade em que o mundo se encontra em nível de desenvolvimento tecnológico, 
mas de um salto da sociosfera ${ }^{7}$ para a noosfera ${ }^{8}$ terrestre. Isto é, sintagmática. Tal passagem "foi possibilitada enfim pelo surgimento súbito e explosivo das tecnologias da informação e da comunicação" (Halévy, 2010, p. 79).

A revolução noética trouxe uma nova maneira de lidar e entender a informação, relacionando-a com a mente humana. Por exemplo, como essa relação é diretamente interligada (Radin, 2012) com os cérebros humanos. Prelúdio anunciado na década de 1990 pelo físico John Archibald Wheeler (1990). Para ele, a relação do indivíduo com o universo, com o mundo, antes de entrar na concepção unitária de matéria e energia; tudo parece ser composto de informação. Com as TIC, as relações e escolhas pós-binárias ${ }^{9}$ tornaram-se totalmente mais complexas, um salto cognitivo. É o novo fenômeno evolutivo cerebral deste século que eclodiu a partir da revolução noética e que influencia diretamente qualquer processo de ensino-aprendizagem no empreendimento de tecnologias de comunicação. Vale lembrar que preocupações em nível instrumental já foram feitas por Palloff \& Pratt (2004). Agora, diante de tais mudanças estabelecidas pela revolução noética e seus fenômenos anunciados, como se poderia potencializar a aprendizagem virtual com as ferramentas já existentes? E mediante quais fundamentos evolutivos se deveria pautar para além do instrumental?

Segundo Halévy, primeiramente, essa evolução humana não é política nem econômica. A priori, encontra-se numa outra esfera. Ela desencadeia uma revolução conceitual da informação como um todo. De maneira sintagmática, são exigidos três aprofundamentos: o filosófico, o ético e o metafísico (ontológico). Um weltanschauung - uma nova percepção/concepção de mundo - que (já) se faz presente para os atores sociais da era do conhecimento/era digital. E, no intuito de não perder tempo, talento e nem dinheiro, urge uma engenharia reversa do conhecimento.

Ou seja, num tempo não muito futuro, será necessário cada vez mais em EaD refletir os anseios ontológicos (de cima) que perpassam todo o processo de instrumentalização a partir das TIC (para baixo). Essa reversão no pensar o processo de engenho do EaD às instituições de ensino é uma premência evolutiva. Pensar a educação em ambiente virtual, on-line e em tempo real, a fim de facilitar o processo de ensino-aprendizagem, é incumbência para uma filosofia da Educação a Distância. Pois, pedagogicamente, pensar os anseios educacionais para o século XXI - seja ele presencial ou virtual - sem uma base filosófica para fomentar o ensino por viés ontológico, seria no mínimo entrópico nos dias atuais. Contudo, não basta apenas inverter esse processo, mas, sim, estar atento e perceber a necessidade de tal inversão (Halévy, 2010). Igualmente, o trabalho de somar forças e unir pedagogia e filosofia cada vez mais.

A partir do momento em que a reflexão for de maneira inversa, de cima para baixo, aí, sim, as novas metodologias, somadas à melhor tecnologia, poderão acolher, de maneira balanceada, as necessidades de aprendizagem do sujeito do Terceiro Milênio. Para transformar a origem de todo esse processo, devese refletir a partir do fenômeno (Gava, 2014a) e, assim, fomentar uma filosofia da Educação a Distância.

7 Trata-se de uma cadeia que perpassa a biosfera, a tecnosfera e, subsequentemente, a sociosfera e a noosfera. Sociosfera seria a camada formada partir das relações humanas e suas construções sociais de interação e organização por meio de instituições políticas e culturais.

8 Noosfera é a camada formada pelo pensamento humano. Responsável pela revolução noética. Alguns autores também costumam relacioná-la com a teoria do inconsciente coletivo, do médico psiquiatra e um dos fundadores da psicanálise, Carl Gustav Jung. O termo noosfera ficou amplamente conhecido - hoje em evidência de estudo por diversas áreas do conhecimento, novamente - pelo paleontólogo e filósofo jesuíta Pierre Teillard de Chardin.

9 Recentemente, em 2015, pesquisadores do Instituto de Tecnologia de Zurique, Suíça, inspirados no processo sináptico de cérebros humanos, conseguiram criar uma espécie de "neurônio artificial" (chamado de memristor) que indica a capacidade de uma lógica pós-binária. Com esse feito, os pesquisadores descobriram que tal elemento pode armazenar informações além da lógica tradicional do bit; 0 ou 1. Afirmam que a descoberta aponta real utilidade para se empreender uma nova fase à tecnologia da informação digital. Seria o denominado "trit". Assim, as informações podem ser codificadas em estados 0, 1 ou 2. Ou seja, em três estados. Esse processo de computação também pode ser usufruído em computação neuromórfica. Inspirações de componentes eletrônicos devindos das sinapses neuronais que processam informação além do binário 0 e 1 . Para outros assuntos relacionados a tecnologia da informação com base nessa descoberta, vide nas referências o site de divulgação tecno-científica: inovação tecnológica. 
Ainda vale destacar que consideradas tais problemáticas, após essa inversão, considerar-se-ão aptos à compreensão da principal questão fenomenológica apresentada nesta pesquisa e que assola o atual momento da política educacional em lidar com o universo da aprendizagem em âmbito virtual a distância: como o advento da informação e seus instrumentos tecnológicos transformaram o cérebro humano, mais especificamente o Cérebro Global.

Antes de tudo, deve-se compreender, com base na denominada virada informacional (Palfrey \& Gasser, 2011), como a noção de transmissão de informação está compassada nos atuais modelos metodológicos de $\mathrm{EaD}$, pois é oferecida em modelos demasiadamente verticais ${ }^{10}$. De fato, o modelo vertical-modular na história filosófico-científica teve a sua contribuição (Bastos, Gava \& Vargas, 2014) para a reflexão dos anseios pedagógicos atuais. Por isso, equívoco seria ainda haver a insistência nesse problemático intrincado modelo vigente. E que, atualmente, essa maneira - anunciada ao ostracismo - contribuiu, de fato, num primeiro momento, à emancipação do ensino em ambiente virtual.

Assim, primeiramente, pode-se compreender a viabilidade de uma nova necessidade educacional aos atores sociais da era digital graças ao acerto da seguinte relação: o processo de aprendizagem pode ser transmitido a distância e de maneira virtual. Este é o primeiro momento e seu acerto.

Vale reforçar ainda, com relação ao que foi explanado no início do primeiro parágrafo desta seção, que a virada informacional ocasionou dois fenômenos que se encontram sinergicamente (Gava \& Bastos, 2015): a era digital e a década do cérebro. Esses dois fenômenos serviram para formar a base do primeiro momento do EaD. Isto é, romper as fronteiras da sala de aula física e pensar as possibilidades de um ensino a distância.

Todavia, o segundo momento no EaD é peculiar e tênue, haja vista que urge significativa atenção para algumas reflexões importantíssimas. Então, exige-se:

1. Buscar compreender e reverter os equívocos do primeiro momento no EaD - mesmo sabendo que a relação foi correta;

2. Fomentar uma nova proposta pedagógica capaz de oferecer metodologia horizontal que estimule o Cérebro Global por meio de plataformas virtuais e outras possibilidades das TIC;

3. Responder aos anseios subjetivos presentes na era digital com base numa fundamentação ontológica e ética acerca da informação aos novos atores sociais.

Pensar conjuntamente cada tópico apresentado acima exige um sistêmico esforço reflexivo (Morin, 2006). Sobretudo o cuidado de não ofuscar o fenômeno nas conjecturas teóricas e axiomáticas (quando não arcaicas), que muitas vezes sobrepõe a própria suspensão do juízo do mundo que se revela - a era do conhecimento.

Frente à era digital e à sua nova demanda fenomenológica anunciada pelas TIC, os setores responsáveis por refletir o EaD em seu âmago ainda carecem de uma engenharia reversa do conhecimento, principalmente por meio de carência filosófica para acompanhar os fenômenos da vida. Se a era digital apresenta-se por meio desse caos de intensa informação, a filosofia na era digital deve servir para dar ordem para essa velocidade infinita da informação infrene e refletir os tópicos éticos envolvidos.

Deixar escapar tais reflexões no atual momento do EaD demonstra a urgência dos transientes envolvidos: instituições e atores sociais. Essa carência envolve sistemicamente o fazer EaD hoje. “Nada é mais doloroso, mais angustiante do que um pensamento que escapa de si, ideias que fogem, que desaparecem apenas esboçadas, já corroídas pelo esquecimento ou precipitadas em outras que também não domina-

10 Fóruns tira-dúvidas de conteúdo e de questões técnicas, bem como mural de recados e percursos de jogos, não seriam mais suficientes para proporcionar processo de ensino ativo e dialógico frente à nova demanda educacional e a seus fenômenos neurocognitivos. 
mos" (Deleuze \& Guattari, 2010, p. 237). O segundo momento em EaD é agora. É urgente o domínio das pautas fenomenológica, ontológica e ética.

\section{Ensino, internet em tempo real e computação quântica: outra revolução que bate à porta}

Agora, ciente do pano de fundo apresentado, o desafio é como se deve refletir sobre as principais mudanças no campo ontológico. Relembrando: o que é "informação"? Quais as influências e as mudanças cognitivas no processo de aprendizagem frente ao Terceiro Milênio? Filosofia da mente e ciência cognitiva devem reforçar suas relações pedagógicas interdisciplinares a fim de direcionar ontológica e epistemologicamente o pano de fundo desta problemática.

O ensino a distância em ambiente virtual está para transmudar, no que há clareza de modo eminencial, a maneira como o processo de ensino-aprendizagem acontecerá com a emergência das TIC. Não haverá espaço para lacunas de caráter ontológico. Trata-se de uma época que requer amadurecimento, um efeito com excelência. Munidos de zelo à compreensão dos esforços ocorridos no primeiro momento em EaD, o ensino em ambiente virtual passa a validar um ato anteriormente inválido à era do conhecimento. Devese reproduzir novas metodologias a partir do fenômeno que escancara nossa realidade: o Cérebro Global e a horizontalidade da informação no processo de criação. Algo que muitos já sentem quando pensam sobre a relação desses fenômenos (Deleuze \& Guattari, 2010).

Todavia, no atual momento, julga-se que a principal dificuldade no pensar em EaD seja a virada informacional. Pois, desde Alan Turing, passando principalmente por Claude Shannon (1949) até Fred Dretske (1981), nossa maneira de pensar acerca do que é informação foi (e ainda é) deveras mecanicista para os tempos atuais (Gonzalez, Broens \& Moraes, 2010). Principalmente quando ainda se observam vestígios desse mecanicismo nas metodologias de ensino vigentes. Mas a principal questão em que urge tênue reflexão à frente da educação do século XXI, devido ao descomunal upgrade das TIC, é a ética informacional. Ou seja, o ethos informacional (Capurro, 2010; Moraes, 2012).

Discutir ontológica e cerebralmente informação é crucial para o novo momento em EaD. Esse segundo tempo exigirá atento zelo para essas questões que, a priori, eram reduto hermético de uma filosofia desvinculada interdisciplinarmente de outras áreas que há tempos poderiam ter sido beneficiadas por esse viés ontológico da informação, a fim de mensurar os fenômenos (éticos, ontológicos, cognitivos etc.) que perpassam o nosso dia a dia na educação virtual e on-line. Mais ainda, em saber que o ethos informacional está diretamente relacionado àqueles que possuem ou não acesso a informação disponível em rede digital (Azevedo et al., 2011; Brandão, Jambeiro, Lima \& Silva, 2005), haja vista (mesmo não sendo o escopo deste artigo) que, de maneira igual, deve-se considerar os anseios da inclusão digital. Pois é comum em EaD encontrar discentes a ter suas primeiras experiências em nível didático com as plataformas AVA - outro problema de evasão e que está diretamente ligado ao ethos informacional desses atores.

Embora ainda discutido ontologicamente em seara da filosofia da informação, o ethos informacional está vinculado à formação desses atores sociais que formam o seu processo de moralidade no mundo a partir das novas tecnologias. O filósofo italiano Luciano Floridi (2014; 2013), pioneiro nas áreas da filosofia da informação e da ética informacional, vem discutindo essas questões sobre a revolução da infosfera e propõe uma filosofia da informação a partir de discussões sobre, por exemplo, as TIC como reontologização da tecnologia. É exatamente essa preocupação que se deve ter em EaD, pois há uma série de fatores que passam pela discussão do Cérebro Global e que afetam e desembocam no campo moral: a ação do sujeito no mundo a partir do acesso à informação. Então o conceito de ethos informacional trata de como o sujeito que está no mundo, em sociedade, se relaciona, acessa e produz a sua própria informação, individual e coletivamente. 
Floridi (2014; 2013), inclusive, prevendo o sopro ontológico da Web 3.0, a partir da revolução informacional - onde tudo é ecologicamente informação -, cunhou a tríade RPT:

1. Resource (fonte): a informação está no mundo e a quantidade de acesso definirá a ação (responsabilidade moral) do ator social que dela usufrui;

2. Product (produto): o ator moral que passa também a produzir informação e se reconhece moralmente a partir de suas ações como sujeito do (no) mundo;

3. Target (alvo): como a ação desse ator moral no mundo influencia e afeta toda a estrutura de uma esfera informacional.

O que isso significa? A preocupação diante de um ethos informacional seria isto: como todas essas mudanças no entendimento informacional do mundo digital para o cotidiano afetam a vida humana (Capurro, 2010). Em EaD, estar-se-ia preparado para suportar essa virada informacional do agente moral que eticamente agora também passa a ser criador ativo de conteúdo no mundo digital.

O âmbito digital passará em breve por tênues mudanças. A tendência horizontal já é uma realidade no meio informacional digital. O ator social on-line passa a ditar as regras a partir de uma moral global (Moraes, 2012). As instituições que fomentam inovar no EaD nos próximos anos deverão estar atentas, porque devem repensar as metodologias verticais de caráter mecanicista e passar a refletir nessa questão informacional, a priori ontológica, tendo em vista que o antigo processo binário de criptografia está comprometido pela computação quântica (Marcacini, 2010). A internet sem fio em tempo real transmitida pela luz é uma realidade viável que revolucionará toda a comunicação. E a computação quântica passa a ser a próxima revolução dentre as TIC. Dados esses que podem ser colhidos por meio das recentes pesquisas divulgadas por instituições como University College London e Massachusetts Institute of Technology (MIT).

Como pensar (um novo modelo para) a educação do Século XXI a partir dessas questões? Nosso modelo vigente de EaD no mundo está preparado para atender tal ruptura, do vertical modular para o global horizontal? Percebe-se, mais do que nunca, o anuncio da Web 4.0. Todos os indivíduos passam a ser, em suas formas de vida, agentes particulares de informação. Agentes que carregam por meio de suas subjetividades e suas ações no mundo a troca de conhecimento são ativos e cocriadores. Novamente, uma questão de caráter ontológico em que a ética informacional traz à tona a preocupação ecológica também. Todos carregam informação - um valor profundo - e passam a compartilhá-la numa infosfera (Halévy, 2010; Moraes, 2012; Floridi, 2013).

\section{Modelo de plataforma horizontal: a possibilidade de uma metodologia neuroglobal para o EaD}

Com base nas corroborações propostas por Howard Gardner (2008) acerca das mudanças cognitivas, atualmente investiga-se a possibilidade de projetar uma plataforma de estímulo neuroglobal, modelo protótipo (Figura 1), e sua viabilidade numa metodologia de gameficação própria a ser oferecida on-line. Levase em consideração a engenharia reversa do conhecimento em todo escopo do projeto, bem como buscase atender às necessidades neurocognitivas da era do conhecimento. A proposta metodológica parte do conteúdo - com a devida coparticipação docente. Todavia, também haverá o espaço desenvolvido pelos próprios discentes, assim como a escolha dos temas das aulas, o calendário e a troca de experiências e conhecimentos próprios entre os atores envolvidos (Figura 2).

Igualmente, a fim de estimular o Cérebro Global e suas funcionalidades entre os contatos informacionais, a nova plataforma ( gameficação) ${ }^{11}$ visa a estimular as seguintes capacidades/funções cognitivas:

11 Ambiente inspirado numa estrutura de jogo, com metodologia exclusiva para atingir resultados práticos. 


\section{Lógica;}

2. Metacognitiva;

3. Representacional (psicológica).

Assim, possibilita-se estimular globalmente os níveis cognitivos do cérebro humano. O modelo neurocognitivo proposto na Figura 1 - de inspiração cibernética - busca o desenvolvimento de uma mente holística (Gava, 2014b) que se apropria da noção de complexidade, integrando o processamento global do cérebro humano e, envolvendo simultaneamente o raciocínio lógico, a criação metacognitiva e a capacidade representacional. Busca-se disponibilizar metodologicamente o uso dessas três funções cognitivas de forma horizontal às disciplinas. Para isso, o ambiente virtual em desenvolvimento deverá atender holisticamente cada função. Então espera-se que a metodologia a ser aplicada no AVA possa estimular o Cérebro Global dos atores sociais da seguinte maneira:

1. Desenvolvimento lógico-racional (córtex pré-frontal e núcleo acumbente): parecer neurocognitivo da primeira função = estimular a região do núcleo acumbente ${ }^{12}$, a estruturação do pensamento crítico, da sensação de motivação e recompensa e a tomada de decisão;

2. Desenvolvimento metacognitivo (jogo cerebral): parecer neurocognitivo da segunda função = o enredo metodológico nesta parte está pautado no estímulo metacognitivo. Ou seja, a heurística será o escopo principal. O estímulo imagético acerca da problemática. As representações criadas devem estimular o próprio questionamento mais livre. Porém, mesmo que haja a possibilidade de criações soltas, estas estarão relacionadas à primeira função;

3. Desenvolvimento psicológico (conexões neurais de médio-longo prazo): parecer neurocognitivo da terceira função = possibilitar o desenvolvimento psicológico da neuroplasticidade, das conexões neurais a partir do estímulo dos processos de aprendizagem nessa metodologia e a possibilidade do potencial mnemônico da livre associação a partir da memória associativa.
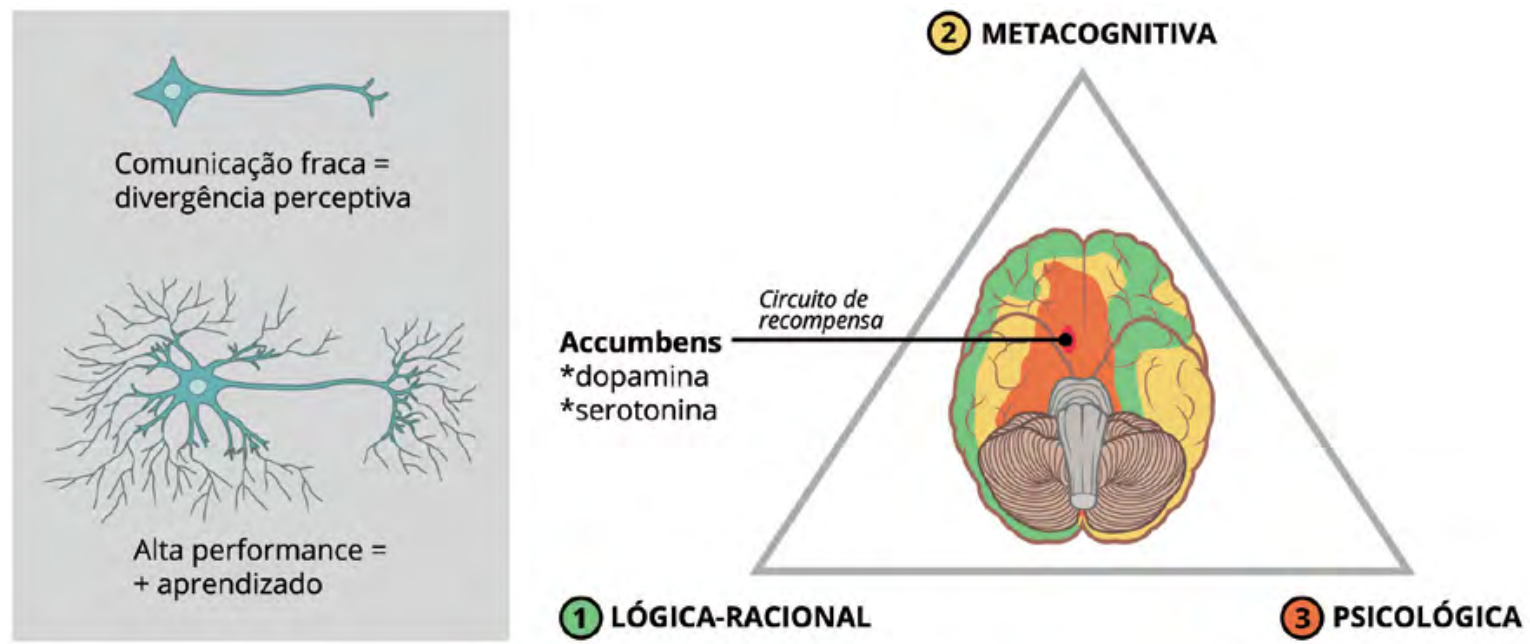

Figura 1: Esquema metodológico neurocognitivo ${ }^{13}$

12 Núcleo que faz parte das regiões do córtex pré-frontal. As regiões frontais são responsáveis pelas tomadas de decisão, pesando as emoções envolvidas (córtex-órbito-frontal), e pela capacidade de projetar um esquema de causas e consequências dos atos. É considerado um dos pontos principais do conhecido sistema de recompensa. Ou seja, quando você tem a ideia de que algo será motivador, o núcleo acumbente estimula a sensação de prazer. Há a liberação de dopamina, responsável pelo processo de aprendizado/memorização.

13 Metodologia em fase piloto de estudo e de aplicação. Na imagem hipotética, do lado esquerdo podemos ver um neurônio na cor verde que foi pouco estimulado modular e metodologicamente no processo de ensino-aprendizagem. Suas ramificações não são suficientes para uma comunicação em potencial. Do lado direito, pode-se visualizar um neurônio em que a neuroplasticidade foi bem-sucedida, com maior potencial de ramificação devido ao estímulo do Cérebro Global. Assim, é capaz de possibilitar maior performance neural no processo de ensino-aprendizagem 


\section{PROTÓTIPO - PLATAFORMA SITUACIONAL}

\section{FILOSOFIA}

Espaço temático

\section{Laboratório de ideias}

\section{Uploads}

Ensaio empreendedor

\section{Reflexão do mês}

ESCOLHA OTEMA PARA A PRÓXIMA AULA

\begin{tabular}{lll}
\hline Consumismo & Tecnologia & Felicidade \\
\hline RANKING & $22 \%$ & \\
\cline { 2 - 2 } & & \\
\hline
\end{tabular}

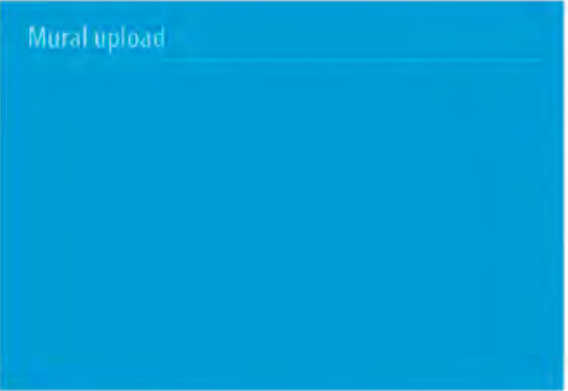

ÉTICA

AMOR

JUSTIÇA

MORAL

MIT0

BELEZA

Figura 2: Parte de um esquema de plataforma situacional on-line neurocognitiva ${ }^{14}$

A fim de possibilitar a validade desse protótipo em desenvolvimento, deve-se estimular um ambiente neurocognitivo horizontal. Citando Gardner (2008, p. 173): "our minds are changed either because we ourselves want to change them or because something happens in our mental life that warrants a change".

O ambiente virtual de aprendizagem da Figura 2 visa apresentar o eixo temático da disciplina dentro de um norteador temático situacional. Ou seja, ao invés de serem modulados e definidos, os discentes passam (influenciados a partir de suas necessidades atuais; de sua própria realidade: ética, política, profissional, existencial, entre outros) a escolher em comum acordo qual será a estrutura de cada aula semanal e/ou quinzenal. A aba "espaço temático", em destaque, representa o sítio onde os discentes - baseados na ementa curricular da disciplina - podem escolher afinidades e situações dentro de um processo de participação e motivação ativa.

Essa horizontalidade temática exige ativa coparticipação e comum acordo entre a turma. Igualmente, acredita-se que possa estimular de forma neurocognitiva a relação temática da ementa e a conexão com a sua atual realidade/necessidade. Inclusive vale lembrar que a estrutura temática da ementa da disciplina está pautada numa referência lógica da metodologia neurocognitiva e, disponibilizada pelo docente. As demais abas se referem às seguintes questões:

1. Laboratório de ideias: espaço destinado para que os discentes possam contribuir com ideias inovadoras e/ou que estejam a ser discutidas recentemente;

2. Uploads: espaço destinado a que os discentes possam subir arquivos diversos e disponibilizar para a discussão da turma. Por exemplo: artigos científicos de terceiros relacionados direta ou indiretamente com a disciplina e/ou com o tema. Artigos, textos, links e reflexões de própria autoria. Nesse espaço, o material bruto da disciplina começa a ser construído por meio da coparticipação entre os discentes e o docente;

14 . Esquema de plataforma da disciplina Filosofia. Protótipo apresentado no $20^{\circ}$ Congresso Internacional ABED de Educação a Distância, nos dias 6 a 9 de outubro de 2014, em Curitiba, PR, Brasil. Título do trabalho: Filosofando na era digital. 
3. Ensaio empreendedor: os discentes disponibilizam suas contribuições (trabalho textual, videodebate, entre outros) a cerca da disciplina aplicada à sua própria realidade, a seu cotidiano;

4. Reflexão do mês: os discentes constroem juntamente com o docente um material de base de encerramento da disciplina. Todos serão autores do próprio conteúdo produzido.

Baseado na fundamentação apresentada ao longo deste trabalho, acredita-se que por meio de uma plataforma situacional horizontalizada, com metodologia neurocognitiva capaz de estimular o Cérebro Global, seja possível atender, em primeiro lugar, os anseios da Web 3.0 dentro de um modelo de tecnologia LMS já existente. O aumento histórico da conectividade emancipou os atores sociais a serem criadores de conteúdos. É fato que o ator social passa a ser cada vez mais ativo e criador.

A complexa tendência nos próximos anos é de que cada vez mais os atores sociais passem a ser sujeitos que já "cresceram em um mundo onde a informação e a comunicação estão disponíveis a quase todas as pessoas e podem ser usadas de maneira ativa" (Veen \& Vrakking, 2009, p. 29). Sendo assim, as passivas modulações e-learning verticais e estáticas não cativam mais esse público. Exatamente "porque o que é complexo não pode ser reduzido por análise a um conjunto de componentes" (Halévy, 2010, p. 43). O desafio atual às disciplinas disponíveis on-line seria possibilitar a criação de plataforma situacional, ativa e coparticipativa. E que estimule neurocognitivamente os processos do Cérebro Global.

\section{Considerações finais}

Acredita-se que a proposta deste artigo possa ter esclarecido que não se está desmerecendo as atuais tecnologias de ponta e suas funcionalidades já presentes nas instituições que oferecem o ensino a distância. Muito menos julgando a maneira como estão sendo utilizadas. O intuito principal foi apontar os anseios ontológicos que estão por detrás de todo o primeiro tempo em EaD. De como as instituições, os discentes e os docentes estão inseridos nesse contexto para uma nova fase, um segundo tempo. E, além dos fenômenos do Cérebro Global, que há outras tênues considerações de como pensar a EaD coma ausência de algumas pautas apresentadas. A possibilidade de aplicação da plataforma horizontal/ situacional é um piloto a ser aprimorado. No atual momento, buscam-se parceiros de desenvolvimento e a contribuição à incubação em uma startup. Adiante, espera-se que seja possível passar por um processo de validação pelo consumidor final.

Destacam-se, ainda, alguns estudos que reforçam a temática desta pesquisa. Como por exemplo um estudo realizado pela Universidade de Berkeley, em que é relatado que, a partir dos anos 2000 em diante, a quantidade de informação produzida por nós, Homo sapiens, está sendo mais elevada, anualmente, do que todos os outros 40 mil anos em que aqui já habitamos. A neurociência cognitiva evidencia que o cérebro mudou nos últimos 35 anos a forma de processamento cognitivo. Os cérebros de indivíduos que nasceram a partir da década de 1990 já são capazes de processar mais conteúdo de maneira horizontal. Ao contrário de outras gerações anteriores à década de 1980, que estavam habituadas a processar conteúdo informacional de maneira verticalizada e monológica. Essa mudança ocorreu com o surgimento das novas tecnologias, com a ascensão das TIC. Vide estudos do The Global Brain Institute.

Com a ascensão da internet em tempo real, a tendência à célere evolução definida por Cérebro Global é uma constatação. E, como mencionado anteriormente, instituições como The Global Brain Institute preocupam-se minuciosamente com a complexidade cognitiva da sociedade da informação. Atualmente, para o EaD, urge pensar modelos metodológicos que estimulem cada vez mais o Cérebro Global.

Algumas plataformas e-learning vigentes ainda se baseiam em metodologias verticalizadas e demasiadamente conteudísticas, num processo neurocognitivo modular passivo. Em consequência disso, pode-se encontrar boa parte das dificuldades atuais em EaD. A metodologia vigente tenta se sustentar com base 
em teorias psicológicas das décadas de 1970 e 1980. A tecnologia até pode ser de última geração disponibilizada pelas diversas instituições que oferecem ensino a distância; entretanto, o ostracismo metodológico está ancorado num padrão neurocognitivo que não condiz com o atual potencial cerebral humano.

\section{Agradecimentos}

Ao professor e pesquisador Pedro Borges de Araújo (Autofocus: neurosciences - architecture - philosophy, Universidade do Porto), pela parceria em pesquisas que incentivam o avanço no refletir educacional e na expansão cognitiva. E, pelo seu pioneirismo e contribuição à EaD em Portugal, bem como seus pares de pesquisa em círculo europeu. Seus apontamentos transdisciplinares influenciaram diretamente esta pesquisa.

\section{Referências bibliográficas}

Abbagnano, N. (2012). Dicionário de filosofia. 6. ed. São Paulo: Martins Fontes.

Azevedo, A. R., Reis, D. B., Lima, G. M., Machado, I. I., Miranda, I. A., Lourenço, J. M. \& Duarte, A. S. (2011). Inclusão digital e competência informacional: proposta de abordagem metodológica para estudo de usuários da informação digital. Múltiplos Olhares em Ciência da Informação, 1(1), 1-14. Disponível em http://portaldeperiodicos.eci.ufmg.br/index.php/moci/article/view/1220/825

Bakhtin, M. (1997). Marxismo e filosofia da linguagem. São Paulo: Hucitec.

Bastos, C. L., Gava, G. L. \& Vargas, C. E. C. (2014). Jerry Fodor and The Reinterpretation of The Phrenological Model. American Journal of Education Research, 2(12), 8-10. doi: 10.12691/education-2-12-3

Brandão, M. A., Jambeiro, O., Lima, J. \& Silvia, H. (2005). Inclusão digital e educação para a competência informacional: uma questão de ética e cidadania. Ci. Inf, 34(1), 28-36. Disponível em http://www.scielo. $\mathrm{br} / \mathrm{pdf} / \mathrm{ci} / \mathrm{v} 34 \mathrm{n} 1 / \mathrm{a} 04 \mathrm{v} 34 \mathrm{n} 1 . \mathrm{pdf}$

Capurro, R. (2010). Desafíos téoricos y practicos de la ética intercultural de la información. In EBook do I Simpósio Brasileiro de Ética da Informação (pp. 11-51). João Pessoa: Idea.

Deleuze, G. \& Guattari, F. (2010). O que é a filosofia. 3. ed. Rio de Janeiro: Editora 34.

Dretske, F. (1981). Knowledge and the flow of information. Cambridge: MIT Press.

Floridi, L. (2013). The ethics of information. UK: Oxford University Press.

Floridi, L. (2014). The fourth revolution: how the infosphere is reshaping human reality. UK: Oxford University Press.

Freire, P. (2011). Extensão ou comunicação? 13. ed. São Paulo: Paz e Terra.

Gardner, H. (1994). Estruturas da mente: a teoria das inteligências múltiplas. Porto Alegre: Artes Médicas.

Gardner, H. (1996). A nova ciência da mente: uma história da revolução cognitiva. 2. ed. São Paulo: Edusp.

Gardner, H. (2008). Changing minds: the art and science of changing our own and other people's minds. Boston: Harvard Business School Press.

Gava, G. L. (2010). O último desejo de Freud: réquiem à teoria do inconsciente. Curitiba: Juruá.

Gava, G. L. (2014a). The Philosophy of Distance Education. American Journal of Educational Research, 2(12), 1-3. doi: 10.12691/education-2-12C-1 
Gava, G. L. (2014b). A mente holística: fenômenos cognitivos globais no cérebro segundo Jerry Fodor. Curitiba: Juruá.

Gava, G. L. (2016). O cérebro global e sua relação com a Educação a Distância. Portal Ciência e Vida - Revista Filosofia, ano IX, n. 117, 1-2. Disponível em http://portalcienciaevida.uol.com.br/esfi/Edicoes/117/ artigo369726-1.asp

Gava, G. L. \& Bastos, C. L. (2015). A disciplina de filosofia no modelo EaD: limites, desafios e possibilidades da disciplina a distância. Saberes - Revista Interdisciplinar de Filosofia e Educação, 1(11), 43-51. Disponível em http://www.periodicos.ufrn.br/saberes/article/view/6349/5195

Gonzalez, M., Broens, M. \& Moraes, J. (2010). A virada informacional na filosofia: alguma novidade no estudo da mente? Aurora Revista de Filosofia, 22(30), 137-151. Disponível em http://www2.pucpr.br/reol/ index.php/RF?dd $1=3697 \&$ dd99 $=$ pdf

Halévy, M. (2010). A era do conhecimento: princípios e reflexões sobre a revolução noética no século XXI. São Paulo: Unesp.

Inovação Tecnológica. Lógica pós-binária: criado um trit, que guarda 0, 1 ou 2. Acesso em 12 de maio de 2016, disponível em http://www.inovacaotecnologica.com.br/noticias/noticia.php?artigo=nanomemoria-trit\#.VzSIW9IrLIV

Lévy, P. (1996). O que é virtual? São Paulo: Ed. 34.

Marcacini, A. (2010) Direito e informática: uma abordagem jurídica sobre a criptografia. São Paulo: CryptoBooks.

Massachusetts Institute of Technology. MIT Technology Review. NSA Says it "must act now" against the quantum computing threat. Acesso em 25 de fevereiro de 2016, disponível em https://www.technologyreview.com/s/600715/nsa-says-it-must-act-now-against-the-quantum-computing-threat/

Moraes, J. A. (2012). Implicações éticas da "virada informacional na filosofia". Dissertação de mestrado. Universidade Estadual Paulista Júlio de Mesquita Filho.

Morin, E. (2006). A cabeça bem-feita: repensar a reforma e reformar o pensamento. 12. ed. Rio de Janeiro: Bertrand Brasil.

Palfrey, J. \& Gasser, U. (2011). Nascidos na era digital: entendendo a primeira geração de nativos digitais. Porto Alegre: Artmed.

Palloff, R. M. \& Pratt, K. (2004). O aluno virtual: um guia para trabalhar com estudantes on-line. Porto Alegre: Artmed.

Prensky, S. (2001). Digital game-based learning. New York: McGraw-Hill.

Radin, D. (2012). Mentes interligadas. São Paulo: Aleph.

Schmidt, E. \& Cohen, J. (2013). A nova era digital: como será o futuro das pessoas, das nações e dos negócios. Rio de Janeiro: Intrínseca.

Shannon, C. \& Weaver, W. (1949). The mathematical theory of communication. Illinois: University Press.

The Global Brain Institute. Acesso em 25 de fevereiro de 2016, disponível em https://sites.google.com/site/ gbialternative1/

University College London. Record for fastest data rate set. Acesso em 25 de fevereiro de 2016, disponível em http://phys.org/news/2016-02-fastest.html 
Veen, W. \& Vrakking, B. (2009). Homo Zappiens: educando na era digital. Porto Alegre: Artmed.

Vygotsky, L. (1998). A formação social da mente. Rio de Janeiro: Martins Fontes.

Wheeler, J. A. (1990). Information, physics, quantum: the search for links. In: Zurek, W. H. (Ed.). Complexity, entropy, and the physics of information. Reading: Perseus Books. 